\title{
Human Capital Creates Insider Power
}

\author{
Joan Muysken, Maastricht University \\ Thomas Zwick, Centre for European Economic Research (ZEW)
}

June 1999

\begin{abstract}
This paper demonstrates that insiders can erect barriers to entry and skim rents by sinking costs in human capital when labour markets are otherwise perfectly contestable. The sunk costs nature of human capital investments may result from the need to satisfy ever increasing specialised skill requirements in our society.

When outsiders can not threat with market entry, insiders invest inefficiently in human capital such that their rent share is maximized. This inefficiency results from the hold-up problem that arises since workers are not residual claimants of the human capital rents. On the other hand, since insiders' investments are negatively correlated with the number of workers, this may lead to higher than efficient investments nevertheless.

When outsiders have an effective entry threat, insiders are forced to accept higher employment of outsiders and share the reduced rents with them. However, full employment is not necessarily reached and in any case investments are higher and social rent is lower than optimal.
\end{abstract}

JEL-codes: J24, J41

Key Words: Insider-Outsider, Human Capital, Rents, Unemployment, Hold-Up

\footnotetext{
${ }^{1}$ We want to thank Simon Gächter and Winfried Vogt for useful comments on earlier drafts of this paper.
} 


\section{Non-technical Summary}

In insider-outsider models the fact that insiders earn rents while outsiders are involuntarily unemployed is explained by arguments like harassment, turnover or entry and exit costs. This paper demonstrates that insiders can erect barriers to entry and skim rents just by investing in human capital, an activity almost every insider regularly undertakes during his or her working life. The key argument here is that investments in human capital can not be re-earned if no adequate job for the skill is found. This means that investors in human capital face the risk to loose the investment costs if they want to be eligible to participate at the labour market. Adequate jobs are increasingly difficult to find for workers loosing their work-place and outsiders who have to invest in skills that are not easy to apply in a broad variety of sectors because the skill requirements in most jobs tend to be more and more specialised.

First a benchmark scenario is developed with a social planner determining the social optimum respecting the reaction functions of the firm and the workers. Here we have full employment and efficient investment in human capital, while the wage determines the distribution of the rent created by the human capital investment.

When outsiders can not threaten with market entry, insiders invest inefficiently in human capital such that their utility is maximized. This inefficiency results on the one hand from the fact that workers can not skim the entire rent that is created by their human capital investment. Insiders have to grant part of the rent to the firm because otherwise the firm would dismiss workers. On the other hand, since insiders' investments are negatively correlated with the number of rivals, this may lead to higher than efficient investments nevertheless.

In a second step, in the insider-outsider model perfect competition between both groups of workers is introduced. Outsiders are perfect competitors for the insiders which means that outsiders are willing to reduce their rents to a minimum in order to be able to enter the labour market and that outsiders have the same opportunities to invest in human capital as insiders. Outsiders have an so-called "effective entry threat" if they can offer a higher profit than that the insiders voluntarily give to the firm in the monopolistic insider case. When outsiders have an effective entry threat, insiders are forced to accept higher employment of outsiders and share rents with them. However, full employment is not necessarily reached and in any case investments are higher and social rent is lower than optimal. 
In a further step the outside option of the outsiders is set to zero in order to show that the results are unchanged when insiders do not have to pay the unemployment benefits the unemployed outsiders earn. 


\section{Introduction}

This paper is motivated by the concern that many tasks which were taken care of in society in a natural way, i.e. without strong formal requirements and specific regulations, nowadays are highly regulated and in a sense over organised. Examples which come to mind are the many functions in the care sector, where formal training is required for each specific task, like child care, psychiatric care and care for the elderly. In the past these developments have led to the formation of strong and influential interest groups which protect their jobs by gaining control over the regulations and skills required to be admitted to the profession. The most outstanding example of this are the medical specialists nowadays. But one should also think of the introduction or upgrading of highly specialised vocations in some apprenticeship fields within the German dual system in recent years. Through that system a continuing split in ever more specialised professions can be observed, especially in attractive areas like administration and sales. Finally the work-rules imposed by trade unions in the UK and the USA in earlier decades of this century fit to our setting.

A consequence of the current developments is that new interest groups of specialised workers will be formed that use these regulations and specific skill requirements to obtain a higher wage. In that way they can reap the benefits of the rents created by specific human capital investment because there is a lack of competition implied by specific skills requirements for different jobs. A typical example in the Netherlands is, for instance, that recently highly specialised medical nurses have formed a firm which rents their services to the hospital where they used to be employed, since they were dissatisfied by the standard salaries provided.

The lack of competition does not necessarily follow from regulations which might prevent access to certain jobs, but in particular from the sunk costs nature of the education required by these regulations. Human capital investments in these specialised tasks are sunk, because they are not rewarded in other areas of the same profession or in other professions. This sunk costs nature generates insider power which can be used to prevent outsiders to enter the specific labour market. Therefore investment in specific human capital provides an additional argument for insider power, which has not yet been developed in the literature. 
In this paper we present a highly stylised model to show how the sunk-costs nature of education might generate insider power and inefficiently high wages. For simplicity we assume that the production in the economy is provided by a single firm which sells its output at a given price. The relevant production factors are the number of employed workers and the amount of human capital per worker.

In order to make the necessity to invest in specific human capital as pervasive as possible, it is assumed that without specific human capital investment, production is not possible. This assumption is introduced to mimic the evolution of ever increasing formal education requirements in the economy.

The firm hires a sufficient number of workers to maximise its profits. Those who are not employed receive unemployment benefits, financed by a lump-sum wage tax. Workers have to invest in specific human capital before they know if they can keep their job and demand a remuneration when they are employed. Human capital investments are specific because workers lose their entire investment when they are unemployed and the outside option is independent of human capital. In order to show that specific human capital investments are sufficient to erect barriers to entry, insiders do not have any of the possibilities to create barriers to entry that have been mentioned by Lindbeck and Snower (1986, 1987, 1988 and 1991). Without the possibility to invest strategically in human capital, insiders would have to allow for entry of all outsiders.

Workers are not the residual claimants of the rents created by their human capital investments, because labour demand of the firm is positively correlated with the rent share. Therefore workers have to grant part of the rent to the firm in order to assure that the firm offers them a job. The rent sharing between workers and firms causes the familiar hold-up problem. On the other hand, as human capital investment is negatively correlated with the number of rivals for jobs, the hold-up problem is alleviated if the number of rivals for jobs is much lower than the efficient full employment. As a consequence workers might even invest too much in human capital.

In order to demonstrate the effects of sunk investments in human capital on social welfare, human capital formation and labour demand, first a benchmark model with full employment and a model with insiders not being threatened by outsiders is constructed. In a second step, outsiders may enter the labour market when they are able to outperform the 
insiders. Here we demonstrate under which circumstances insiders are able to erect barriers to entry nevertheless and how the entry threat of the outsiders affects the behaviour of the insiders.

\section{The Model}

We assume an economy which consists of a single firm and a labour force of $N$ persons. The risk-neutral agents maximise their objective functions taking the reactions of the other agents into account.

\subsection{The Problem of the Firm}

There is one firm that maximises profit $\pi$. For simplicity let the production function of the firm be of a Cobb-Douglas type. The relevant production factors are the number of employed workers $l$ and the amount of human capital per worker $c$. The firm decides on the number of workers it will employ, and only accepts workers with the same amount of human capital and demanding the same remuneration? The firm has to pay a wage $w$ per unit of human capital.

The profit function of the firm reads as:

$$
\pi=l^{\alpha} c^{1-\alpha}-w c l
$$

with $0<\alpha<1$. Here the given price of the good produced is normalised to unity.

From the profit function of the firm (1) demand for labour can be derived from the first order condition with respect to $l$ :

$$
l=\left(\frac{\alpha}{w c^{\alpha}}\right)^{\frac{1}{1-\alpha}} .
$$

The impact of investment in human capital $c$ on labour demand $l$ is negative, since human capital and labour are substitutes.

\footnotetext{
1 This production function is virtually the same as in Lindbeck and Snower (1991) p. 194. The only difference is the interpretation of the productivity coefficient $c$ as investment in human capital instead of effort.

2 The assumption that the firm accepts only a homogeneous labour force with the same wage level and human capital endowment is frequently made, compare e.g. Carruth and Oswald (1987) or Gottfries and Horn (1987).
} 


\subsection{The Problem of the Workers}

The focus of this paper is on market power of workers when investments in human capital entail sunk costs. Workers have to invest in human capital before they know if they can keep their job or can get a job anyhow. The outside option of all workers is unemployment, whereas the unemployment benefit $\underline{\underline{s}}$ is independent of human capital.

Investment costs in human capital are sunk, because the investments can not be reearned when no adequate job for the specialisation can be found or the job is lost. Virtually all investments in human capital entail elements of sunk costs-even if we would introduce other firms in the model that are interested in the worker-because not all skills and specific knowledge are needed in a different working environment. This is a consequence of the growing specialisation in certain professions that does not allow workers to switch easily from one job with a specific skills requirement to another. In this model all human capital investments are assumed to be sunk costs.

The $N$ homogeneous risk-neutral workers optimise their surplus that is defined as their income minus the costs of investment in human capital and minus taxes. Income is wages $w$ multiplied by the level of human capital $c$. We assume that investments in human capital show decreasing returns to scale. This is frequently found in empirical studies.

For analytical convenience, we assume that the costs of investment are quadratic in the amount of human capital, $c$, with a shift parameter $(1+r)$, i.e., $(1+r) c^{2}$. Taxes $T$ have to be paid by each employed worker in order to provide the unemployment benefit $\underline{s}$ each unemployed worker receives:

$$
T=\underline{s}\left(\frac{N-l}{l}\right) \text {. }
$$

The surplus function $s$ is consequently defined as:

$$
s=w c-(1+r) c^{2}-T .
$$

\footnotetext{
${ }^{3}$ We do not distinguish between specific and general human capital since we assume an economy with a single firm.

${ }^{4}$ See Willis (1986) p. 536 for a survey. Decreasing returns to scale are also widely used in theoretical specifications, compare e.g. Hart and Moutos (1995) p. 16 or Becker (1983) p. 53.

${ }^{5}$ In section 5 we analyse the special case of zero benefits and taxes.
} 


\section{Optimum}

A typical benchmark case is to introduce a social planner that maximises the sum of worker and firm rent, i.e. the total rent $R=\pi+l s$ that results from investment in human capital. One sees that the unemployment benefit is not a part of social rent, because it is merely redistributed between workers and unemployed. Wage payments from the firm to the workers are also purely re-distributive and do not contribute to the social rent. The objective function of the social planner is therefore defined by:

$$
R=l^{\alpha} c^{1-\alpha}-(1+r) l c^{2} .
$$

Total rent is maximised with respect to $l$ and $c$, with the restriction that $l \leq N$. We find that the rent $R$ is increasing in $l$, if we take the condition $\partial R / \partial c=0$ into account and if $\alpha>1 / 3$. We assume the latter to be the case, that is we assume labour productivity $\alpha$ to be large enough. Therefore underemployment is ruled out in the optimum.

In the relevant full employment case, total rent $R^{F}$ is defined as:

$$
R^{F}=N^{\alpha} c^{1-\alpha}-(1+r) N c^{2} .
$$

Optimal investment in human capital $c^{*}$ is found by maximising equation (6) with respect

to $c$ :

$$
c^{*}=\left(\frac{1-\alpha}{2 N^{1-\alpha}(1+r)}\right)^{\frac{1}{1+\alpha}} .
$$

As might be expected, optimal investment decreases with the number of workers $N$ and investment costs $1+r$. Substitution of $c^{*}$ in (6) then yields the optimal social rent $R^{*}$. 


$$
R^{*}=(1+\alpha) \Omega^{\frac{1}{1+\alpha}} N^{\frac{3 \alpha-1}{1+\alpha}}
$$

with

$$
\Omega=\frac{1}{4}\left(\frac{1-\alpha}{1+r}\right)^{1-\alpha} .
$$

Notice that $R^{*}$ and $c^{*}$ are independent of the unemployment benefit $\underline{S}$ since full employment always prevails in the social optimum.

The optimum results are also obtained if the firm determines maximum profits at $l=$ $N$ by setting $c$. The resulting investment then is $c^{*}$ and the maximum profit $\pi^{*}$ in this case is given by

$$
\pi^{*}=R^{*}-\underline{s} N
$$

Here the entire rent accrues to the firm, while workers only earn their outside option $\underline{s}$. Hence maximum profit $\pi^{*}$ is a decreasing function of $\underline{s}$.

The aggregate outside option of the workers never can be higher than the optimal rent $R^{*}$, because $\pi^{*}=0$ should hold. The maximum outside option $s^{\max }$ is therefore defined as:

$$
S^{\max }=\frac{R^{*}}{N}
$$

It seems reasonable to assume that $\underline{s}<s^{\max }$ should hold, because otherwise the entire rent would not be sufficient to grant the outside option to all workers. The outside option $\underline{s}$ is defined for convenience as share $\varepsilon$ of $s^{\max }$ :

$$
\underline{S}=\varepsilon(1+\alpha) \Omega^{\frac{1}{1+\alpha}} N^{\frac{2 \alpha-2}{1+\alpha}} .
$$

with $\varepsilon$ in $[0,1]$.

Now the results of the optimum can be compared to the insider-outsider model. 


\section{Insider-Outsider Model}

We know from labour market bargaining models that inefficiencies are incurred by antagonistic interests of bargaining partners if agents have the right to determine only a part of the variables. In the insider-outsider model, insiders and outsiders determine human capital investments and wage demand, while the firm determines labour demand. Insiders have to commit themselves first by investing in human capital, while outsiders can observe the behaviour of the insiders. Crucial is that for all workers investment takes place before they know whether they will be (re)employed or not. Besides the mover asymmetry, both groups of workers are identical and there are no barriers to entry for outsiders.

In order to assess labour market inefficiencies caused by insiders, in section 4.22 an insider-outsider model is constructed where outsiders are not able to underbid the offer of the insiders. ${ }^{6}$ In a next step it is shown whether underbidding of outsiders has an impact on employment and labour market performance. First the decision structure is elaborated.

\subsection{The Sequence of Decisions}

From now on, it is assumed that $n$ insiders were employed in the previous period, while $N-$ $n=m$ outsiders were unemployed. Apart from their labour market status, insiders and outsiders are identical. For simplicity, and analogous to other insider-outsider models, outsiders and insiders are homogeneous and insiders act as a group that maximises the (expected) surplus of all group members. We assume that workers can determine their human capital investment themselves which is consistent to human capital theory. Moreover, insiders and outsiders can set their wage demand as a take it or leave it offer. Insiders set their wage demand and investment in human capital before the outsiders. The outsiders therefore know the offer of the insiders when they set their choice variables. They invest in human capital if there is a chance to get a job and investment costs are smaller than the expected revenues of investing in human capital. Finally the firm decides how many people and which ones to employ.

\footnotetext{
${ }^{6}$ This assumption is frequently made, compare e.g. Blanchard and Summers (1986), Gottfries and Horn (1987) or Carruth and Oswald (1987).
} 
In section $4.3 \$$, outsiders may underbid the wage demand of the insiders or match (imitate) it. If outsiders underbid the wage offer of the insiders, the firm replaces all insiders by outsiders, provided profits increase. The firm can not replace only some insiders, because all insiders offer the same wage/human capital combination and the firm only accepts a homogeneous workforce. If outsiders imitate insiders, outsiders are hired to the extent that the labour demand of the firm is larger than the number of insiders.

\subsection{Insiders Are Monopolists}

As mentioned above, first the labour market equilibrium is derived for the case that outsiders "are not allowed to" underbid the insiders and insiders therefore enjoy monopolistic market power. The monopolistic insiders choose a level of human capital such that they maximise their surplus. Hence the $n$ insiders maximise (4) with respect to $c$, taking labour demand of the firm $l(2)$ into account:

$$
c^{m o n}=\left(\frac{\alpha(1-\alpha)}{2(1+r) n^{1-\alpha}}\right)^{\frac{1}{1+\alpha}} .
$$

The surplus of the monopolistic workers then is determined by substituting (12) into (3):

$$
S^{m o n}=(1+\alpha) \alpha^{\frac{2}{1+\alpha}} \Omega^{\frac{1}{1+\alpha}} n^{\frac{-2(1-\alpha)}{1+\alpha}}-\left(\frac{N-n}{n}\right)_{\underline{s}} .
$$

The surplus of the monopolistic insiders increases first with labour demand and hence increases initially with the number of insiders. ${ }^{\square}$ It then decreases after the peak at $n^{\text {min }}$ (compare the surplus function in the bottom half of Figure 1):

$$
\frac{n^{\min }}{N}=\left(\frac{\varepsilon(1+\alpha)}{2(1-\alpha)}\right)^{\frac{1+\alpha}{3 \alpha-1}} .
$$

to a level $s^{c o p}$. This surplus level is found when full employment prevails in the monopolistic insiders case: that is, $n=N$ does hold and there are no outsiders. We call this

\footnotetext{
${ }^{7}$ Notice that $s^{m o n} \geq \underline{s}$ has to hold. That is, the workforce should exceed at least $\underline{n}$ in the bottom half of Figure 1 .
} 
case full co-operation, because anybody is co-operating. The surplus of the insiders $s^{c o p}$ is given by:

$$
S^{c o p}=\frac{\alpha^{\frac{2}{1+\alpha}}}{\varepsilon} \underline{S} .
$$

The corresponding level of social welfare $R^{c o p}$ is derived by substituting (12) into (6): ${ }^{\text {. }}$

$$
R^{c o p}=\alpha^{\frac{1-\alpha}{1+\alpha}} \frac{\alpha^{2}-\alpha+2}{1+\alpha} R^{*}
$$

Notice that $R^{c o p}<R^{*}$ although there is full employment. The lower than optimal social rent is caused by inefficient investment of the monopolistic workers. This inefficiency results from the fact that labour demand $l$ is set by the employers, while investment in human capital $c$ is set by the workers. As a consequence, neither employers nor insiders can skim the entire rent from human capital investments. This creates the familiar hold-up problem. For that reason insiders' investment is negatively biased by a factor $\alpha^{1 /(1+\alpha)}$ at full employment - compare (7) and (12). However, investment decreases with the number of workers and therefore $c^{\text {mon }}$ may be even higher than $c^{*}$, if the number of insiders is small enough. Thus the hold-up problem may be even more than compensated by the smaller rivalry effect between insiders if $n / N<\alpha^{1 /(1+\alpha)}$.

If the exogeneously given number of insiders $n$ is smaller than $n^{\min }$, it is in the interest of the monopolistic insiders to let outsiders into the labour market until the number of workers equals $n^{\min }$. This is a consequence of the fact that insiders have to pay taxes for the unemployment benefits to outsiders. ${ }^{10}$ Those taxes may be very high if few insiders have to pay for many unemployed outsiders. However, those outsiders who are not allowed to work by the monopolistic insiders are involuntarily unemployed, because the insiders earn more than the outsiders. Outsiders would work for a lower wage while they cannot underbid the insiders by assumption.

\footnotetext{
${ }^{8}$ It can be shown straightforward that $s^{c o p}>\underline{s}$.

${ }^{9}$ Note that the profit of the firm in the cooperation case equals (compare Figure 1): $\pi^{\text {cop }}=\frac{1}{1-\varepsilon} \alpha^{\frac{1-\alpha}{1+\alpha}} \frac{2(1-\alpha)}{1+\alpha} \pi^{*}$.

${ }^{10}$ In section 5 we show that in when no taxes are raised and no benfits provided, this effect will not occur.
} 
From (14) it is clear that in the monopolistic insider case full employment is optimal, if the unemployment benefit for outsiders is high enough - i.e. $\mathcal{E}$ is so high that $n^{\min } \geq N$

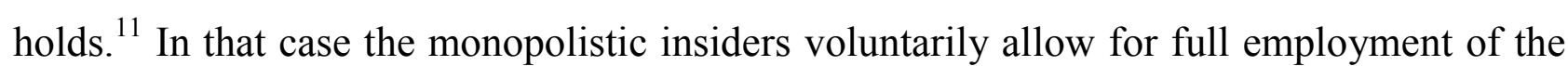
outsiders, even if outsiders are not able to underbid them. This is not the case, if $n^{\min }<N$. In the next part, we show the consequences of underbidding outsiders.

\subsection{Insiders Are Contested by Outsiders}

When outsiders have the possibility to underbid the insiders and $n^{\min }<N$, insiders may be forced to allow more outsiders into the labour market than the optimal $n^{\min }$. This is the case, if it would be otherwise beneficial for outsiders to underbid them and if underbidding is possible, that means the entry threat is effective. By allowing a higher number of outsiders into the labour market, insiders induce outsiders with an effective entry threat to imitate insiders' behaviour instead of outperforming them. Outsiders imitate the insiders, if this grants them a higher surplus than their outside option and a lower surplus than if they outperform the insiders by offering a higher profit to the firm.

\section{Outsider Threat}

In this section the maximum profit that outsiders can offer is derived, in order to see when the entry threat of the outsiders is effective. Outsiders do not necessarily offer this maximum profit and do not always operate as a group, but insiders have to take into account the possibility that outsiders outperform them if insiders offer less than the maximum profit of the outsiders derived below. As the profit of the firm increases with the number of workers, the threat of the outsiders to replace the insiders increases also with their number. In addition the profit offered by the outsiders increases when their rent decreases. The maximum threat point of the $m$ outsiders is therefore found when all outsiders set their surplus equal to $\underline{s}$. As a consequence, we find that for outsiders' threat point it has to hold - compare (14):

$$
w c=(1+r) c^{2}+\frac{N}{m} \underline{s} .
$$

${ }^{11}$ This is the case, if $\varepsilon \geq \alpha^{\frac{2}{1+\alpha}}\left|\frac{2(1-\alpha)}{1+\alpha}\right|$. 
In order to calculate the entry threat, we maximise the profit of the firm under the above constraint (17), i.e. that the outsiders earn their outside option $\underline{s}$, and restricting the number of workers equal to $m$. The human capital investment per outsider that maximises the profit of the firm then is found to be:

$$
c^{\text {out }}=\left({\frac{1-\alpha}{2(1+r) m^{1-\alpha}}}^{\frac{1}{1+\alpha}},\right.
$$

which is higher than efficient (compare the optimum case (7)). As the hold-up problem described in section 4.2 does not apply for the calculation of the threat point, outside investment is unambiguously higher than efficient, because there are less rivals than in the optimum.

The maximum profits the outsiders can offer (the threat point) are:

$$
\pi^{\text {out }}=(1+\alpha) \Omega^{\frac{1}{1+\alpha}} m^{\frac{3 \alpha-1}{1+\alpha}}-\underline{s} N
$$

Notice that $\pi^{\text {out }}=\pi^{*}$, if $m=N$; i.e. the profit of the firm is at the maximum and we reach all optimum results if there are no insiders (compare Figure 1). There also is a minimum number of outsiders required to generate a positive profit since unemployment compensation of insiders has to be paid for, too.

In order to avoid entry, the insiders have to offer at least $\pi^{\text {out }}$. As insiders can mimic outsider behaviour, the maximum profit offer $\pi^{\text {ins }}$ of the insiders is symmetric to that of the outsiders. Therefore we have to rotate $\pi^{\text {out }}$ around $n=1 / 2 N$ in Figure 1 in order to obtain the maximum profit insiders can offer as an answer to the outsider entry threat, $\pi^{\text {ins }}$. One sees immediately that insiders do not have an opportunity to keep outsiders out if $n<1 / 2 N$ since then they can never offer a profit to the firm above $\pi^{\text {out }}$. As a consequence, insiders are always replaced by outsiders, if $m>1 / 2 N$.

The possibility of the outsiders to underbid the insiders only has an effect on the behaviour of the insiders, if $\pi^{\text {out }}$ is larger than the profit $\pi^{\text {mon }}$ the monopolistic insiders offer voluntarily to the firm in order to stay employed. Therefore, we call the entry of the

\footnotetext{
${ }^{12}$ This implies that $m / N>\varepsilon^{1+\alpha /(3 \alpha-1)}$ has to hold.
} 
outsiders effective, if $\pi^{\text {out }}>\pi^{\text {mon }}$. It is clear from Figure 1 that the entry threat of the outsiders is effective when the number of insiders is smaller than $n^{\text {out }}$. 13

It can not be said beforehand, whether $n^{\text {out }}$ is smaller or larger than $1 / 2 N$. It can be shown, however, that if $n^{\text {out }}<1 / 2 N$, the minimum number of workers, insiders voluntarily allow into the firm $n^{\min }$ exceeds $1 / 2 N$ - and vice versa. Hence two cases can be distinguished.

In the first case $n^{\text {out }}<1 / 2 N<n^{\text {min }}$ holds. From the above analysis it then follows that the number of insiders will be $n^{i n s}=\max \left[n, n^{\min }\right]$ and consequently $\pi^{\text {mon }}$ is always valid. In this case the outsider threat does not have an impact on insider behaviour.

The most interesting case from our point of view, however, is when $n^{\min }<1 / 2 N<n^{\text {out }}$. For in this situation, which is depicted in the upper part of Figure 1, outsiders do have an impact on insider behaviour when $n<n^{\text {out }}$, while insiders have the possibility to avoid outsider entry by modifying their behaviour. Insiders are forced to allow for the employment of more outsiders than $n^{\text {min }}$ here in order to keep their jobs. In this case, insiders maximise their surplus with the restrictions that their profit offer is at least equal to $\pi^{\text {out }}$ and labour demand is at least the number of insiders. We can show that the resulting surplus of the insiders $s^{\text {ins }}$ equals $\underline{s}$, if $n=1 / 2 N$ and it equals $s^{\text {mon }}$, if $n=n^{\text {out }}$-compare points A and B, respectively, in Figure 1. ${ }^{14}$ As the resulting insider surplus increases with the number of outsiders allowed into the labour market until $n=n^{\text {out }}$, insiders allow for the entry of $n^{\text {out }}-n$ outsiders. The insiders' surplus with an effective outsider entry threat is therefore reduced from $s^{\text {mon }}$ at $n$ to $s^{\text {mon }}$ at $n^{\text {out }}$. In addition, insiders' investments are equal to $c^{\text {mon }}$ at $n^{\text {out }}$ instead of $n^{\text {mon }}$ and social welfare also increases to $\mathrm{R}^{\text {mon }}$ at $n^{\text {out }}$.

We can show that the outsiders prefer to imitate the behaviour of the insiders because the expected surplus is higher than the surplus, which they would obtain otherwise. The only other option of the outsiders is not to invest at all in human capital and stay out of

${ }^{13}$ The number $n^{\text {out }}$ is given implicitly by: $\frac{\left|1-\frac{n^{\text {out }}}{N}\right|^{\frac{3 \alpha-1}{1+\alpha}}-\varepsilon}{\left(\frac{n^{\text {out }}}{N}\right)^{\frac{3 \alpha-1}{1+\alpha}}}=2\left(\frac{1-\alpha}{1+\alpha}\right) \alpha^{\frac{1-\alpha}{1+\alpha}}$.

${ }^{14}$ It is unclear however, if $\partial s^{i n s} / \partial n>0$ in the range $\left[n^{\min }, n^{\text {out }}\right]$ as depicted in Figure 1 or whether it has a maximum with a surplus above $B$ within this range. In the latter case $s^{\text {ins }}$ has a maximum at say $n^{\text {opt }}$ with $n^{\text {min }}<n^{\text {opt }}<n^{\text {out }}$, and in the following discussion $n^{\text {out }}$ should be replaced by $n^{\text {opt }}$. 
the labour market because underbidding is no viable option when $n^{\min }<1 / 2 N<n^{\text {out }}$. Therefore the outside option of the outsiders when they do not imitate is $\underline{\mathbf{s}}$. The imitation strategy is beneficial because even in the worst case, when only one outsider is accepted (this is the case if $n^{\text {out }}=n+1$ ) while all outsiders imitate the insiders and invest in human capital the expected surplus of all outsiders is above $\underline{s}$. In other words: the rent $s^{\text {mon }}-\underline{s}$ earned by one outsider allowed into the labour market is higher than the total investment costs of all outsiders $m(1+r) c^{m o n}$ at $n^{\text {out }}$.

The results of the above discussion are summarised in Table 1 . We concentrate on the situation that there are sufficient insiders, i.e. $n \geq 1 / 2 N$, otherwise outsiders will replace the insiders immediately. One then sees that some outsiders will be allowed to entry when the number of insiders is not very large, that is either $1 / 2 N<n<n^{\min }$ or $1 / 2 N<n<n^{\text {out }}$ should hold. However, one also sees that it is only in the latter case that the outsider threat is effective in the sense that insiders cannot longer behave in a monopolistic way. This situation is characterised by not too large a number of insiders, whose monopolistic behaviour will leave insufficient profits for the firm compared to the profits outsiders can offer. In that case the insiders will have to invest inefficiently more in human capital in order to generate higher profits for the firm and may also allow some outsiders in.

Table 1 Insiders' behaviour and outside threat

\begin{tabular}{|l|c|c|c|c|}
\cline { 2 - 5 } \multicolumn{1}{c|}{} & \multicolumn{2}{c|}{$n^{\text {out }}<1 / 2 N<n^{\text {min }}$} & \multicolumn{2}{c|}{$n^{\text {min }}<1 / 2 N<n^{\text {out }}$} \\
\cline { 2 - 5 } & $1 / 2 N<n<n^{\text {min }}$ & $n \geq n^{\text {min }}$ & $1 / 2 N<n<n^{\text {out }}$ & $n \geq n^{\text {out }}$ \\
\hline Employment & $n^{\text {min }}$ & $N$ & $n^{\text {out }}$ & $n$ \\
\hline Outsiders entry & $n^{\text {min }}-n$ & 0 & $n^{\text {out }}-n$ & 0 \\
\hline Profit & $\pi^{\text {mon }}\left(n^{\text {min }}\right)$ & $\pi^{\text {mon }}(n)$ & $\pi^{\text {out }}\left(n^{\text {out }}\right)$ & $\pi^{\text {mon }}(n)$ \\
\hline Human capital & $c^{\text {mon }}\left(n^{\text {min }}\right)$ & $c^{\text {mon }}(n)$ & $c^{\text {ins }}\left(n^{\text {out }}\right)$ & $c^{\text {mon }}(n)$ \\
\hline
\end{tabular}




\section{The Case without Taxes and Benefits}

In this section, we show that an inefficient regime also is obtained if the outside option $\underline{s}$ equals zero and therefore employees do not have to pay taxes $T$ for the unemployment benefit. In this case, $n^{\min }=0$ and the surplus of the monopolistic insiders decreases always in $n$. The profit functions of the firm $\pi^{i n s}$ and $\pi^{o u t}$ intersect the horizontal axis at the origin and $N$ respectively, while $\pi^{m o n}$ is unchanged (compare Figure 2).

The problem of the firm is unchanged, while the surplus of the workers changes to compare equation (4):

$$
s=w c-(1+r) c^{2} .
$$

In the social optimum, all workers are employed and therefore no taxes have to be paid and nothing is changed with respect to $c^{*}$ and $R^{*}$ - compare (7) and (8), respectively. The maximum profit of the firm in the optimum, $\pi^{*}$, becomes equal to $R^{*}$, however.

Although the monopolistic insiders do not have to pay taxes for the unemployed outsiders here, the monopolistic insiders' optimal investment $c^{m o n}$ is unaffected. However, the surplus $s^{m o n}$ increases because taxes no longer have to be paid out of it. It is equal to equation (13) without the last part on the right hand side. Moreover, because of the rivalry effects between the insiders, the surplus always decreases with labour demand (compare the bottom half of Figure 2). Therefore it is never in the interest of the insiders to allow for outsider entry when outsiders are not allowed to underbid insiders, which also means that $n^{\min }=0$. The profit of the firm increases analogously with the number of insiders $n$.

When the number of monopolistic insiders is $N$ (this is analogous to the co-operation case in chapter 4.2, the surplus of the monopolistic insider $s^{c o p}$ equals:

$$
s^{c o p}=(1+\alpha) \alpha^{\frac{2}{1+\alpha}} \Omega^{\frac{1}{1+\alpha}} N^{\frac{-2(1-\alpha)}{1+\alpha}} .
$$

This surplus obviously exceeds the outside option, since it is positive. Social welfare at the co-operation point $R^{c o p}$ is still the same and therefore lower than $R^{*}$. However, the profit of the firm now equals:

$$
\pi^{c o p}=\alpha^{\frac{1-\alpha}{1+\alpha}} \frac{2(1-\alpha)}{1+\alpha} \pi^{*}
$$


In order to calculate the threat point, the wage for the insiders only has to compensate for the human capital investments, or $w c=(1+r) c^{2}$ instead of (17). Outsiders' optimal investment $c^{\text {out }}$ is unchanged, while the threat point is equal to equation (19) without unemployment payments (the last element on the right hand side). The threat point decreases therefore monotonically with the number of outsiders and equals zero when there are no outsiders (compare Figure 2). The same applies for the maximum profit offered by the insiders $\pi^{i n s}$, which is simply rotated around $1 / 2 N$.

The threat point of the outsiders is effective again if the number of insiders is less than $n^{\text {out }}$ where $\pi^{\text {out }}>\pi^{\text {mon }}$. That is, $n^{\text {out }}$ is at:

$$
n^{\text {out }}=\frac{N}{1+\alpha^{\frac{1-\alpha}{3 \alpha-1}}\left(2 \frac{1-\alpha}{1+\alpha}\right)^{\frac{1+\alpha}{3 \alpha-1}},}
$$

which is larger than $1 / 2 N$. Notice that $\pi^{\rho u t}$ equals 1 at $\alpha=1 / 3$ and $\alpha=1$ and describes a Ucurve between with a minimum of $\approx 0.83$ at $\alpha \approx 0.61$.

It can be shown again, that the associated surplus of the insiders with an effective outsider threat equals the surplus enjoyed from the monopolistic insiders $s^{\text {mon }}$ at $n^{\text {out }}-$ compare point $\mathrm{B}$ in Figure 2.15 If there are more outsiders, the surplus of the insiders decreases until zero at $m=1 / 2 N$ (point A) when the insiders want to exclude all outsiders form the labour market. Therefore it is always in the interest of the insiders to allow $n^{\text {out }}-n$ insiders into the labour market, when the entry threat of the outsiders is effective, because this gives them the maximum surplus. The investment in human capital of the insiders is $\mathrm{c}^{\text {mon }}$ at $n^{\text {out }}$ and is therefore lower when the entry threat of the outsiders is effective than in the monopolistic insiders case.

Hence, if the number of insiders is between $1 / 2 \mathrm{~N}$ and $n^{\text {out }}$, insiders can avoid to be replaced by the outsiders by allowing $n-n^{\text {out }}$ outsiders into the firm. Again, it is in the interest of the outsiders to imitate the behaviour of the outsiders even if the consequence is that all outsiders have to invest $\mathrm{c}^{\text {mon }}$ at $n^{\text {out }}$ while only few outsiders have the possibility to enter the labour market. The surplus of the insiders is then reduced from $s^{\text {mon }}$ at $n$ to $s^{\text {mon }}$ at $n^{\text {out }}$ by the effective entry threat of the outsiders, while the profit of the firm increases accordingly to $\pi^{\text {mon }}$ at $n^{\text {out }}$. Social welfare increases, too, from $\mathrm{R}^{\text {mon }}$ at $n$ to $\mathrm{R}^{\text {mon }}$ at $n^{\text {out }}$. 


\section{Conclusions}

This paper demonstrates that the necessity of investment in human capital is an additional reason for the existence of insider market power and labour market inefficiencies.

The insider-outsider model shows that involuntary unemployment is created by sunk investment costs in human capital even if we exclude all reasons identified by Lindbeck and Snower and others which give rise to insider market power. When it is assumed that outsiders can not underbid the offer of the insiders, it is advantageous for the monopolistic insiders to keep labour demand at a minimum number of workers (that may include outsiders when $\underline{s}>0$ ), because a higher labour demand can only be achieved by a higher rent share granted to the firm.

Monopolistic insiders invest inefficiently in human capital. On the one hand their investment is negatively biased, because they have to grant part of the rent generated by the investment to the firm in order to secure their re-employment (this is the hold-up problem). On the other hand, their investment is higher than optimal, because human capital creation is negatively correlated with the number of rivals and labour demand is reduced.

When outsiders underbid the profit offer of the insiders, insiders may be forced to allow labour demand to rise above the minimum number of workers. Otherwise they may be outperformed and replaced by outsiders. Outsiders only pose an effective entry threat however if their number is large enough and the unemployment benefit is low. If insiders have to allow for more outsider employment than they voluntarily would do without outsider underbidding, social welfare increases (but never reaches the optimal level). We still have involuntary unemployment, however and the investment in human capital decreases with the number of additional rivals that enter the labour market.

In our analysis strategic human capital investments alone constitute barriers to entry. Frequently it is argued that insiders can defend their rents, because they have an advantage in human capital endowment. This advantage may originate from learning on the job or inside knowledge of the firm's organisation. These arguments of course add to the potential of human capital to create market power of insiders.

\footnotetext{
${ }^{15}$ The same holds as in note 15 above.
} 


\section{References}

Olivier Blanchard and Lawrence Summers: Hysteresis and the European Unemployment Problem, in: NBER Macroeconomic Annuals, Stanley Fischer (ed.), Cambridge, Mass.: MIT Press, pp. 23-78, 1986

Gary Becker: Human Capital, Chicago: The University of Chicago Press, 2nd edition, 1983

Alan Carruth and Andrew Oswald: On Union Preferences and Labour Market Models: Insiders and Outsiders, in: Economic Journal, 97, pp. 431-445, 1987

Nils Gottfries and Henrik Horn: Wage Formation and the Persistence of Unemployment, in: Economic Journal, 97, pp. 877-884, 1987

Robert Hart and Thomas Moutos: Human Capital, Employment and Bargaining, Cambridge: Cambridge University Press, 1995

Assar Lindbeck and Dennis Snower: Wage Setting, Unemployment, and Insider-Outsider Relations, in: American Economic Review, 76, pp. 235-239, 1986

Assar Lindbeck and Dennis Snower: Efficiency Wages Versus Insiders and Outsiders, in: European Economic Review, 31, pp. 407-416, 1987

Assar Lindbeck and Dennis Snower: Cooperation, Harassment, and Involuntary Unemployment: An Insider-Outsider Approach, in: American Economic Review, 78, pp. $167-188,1988$

Assar Lindbeck and Dennis Snower: Interactions between the Efficiency Wage and InsiderOutsider Theories, in: Economics Letters, 37, pp. 193-196, 1991 
Robert Willis: Wage Determinants: A Survey and Reinterpretation of Human Capital Earnings Functions, in: Handbook of Labour Economics, Orley Ashenfelter and Richard Layard (eds.), Amsterdam: Elsevier, pp. 525-602, 1986 
Figure 1 Insiders' profits and surplus
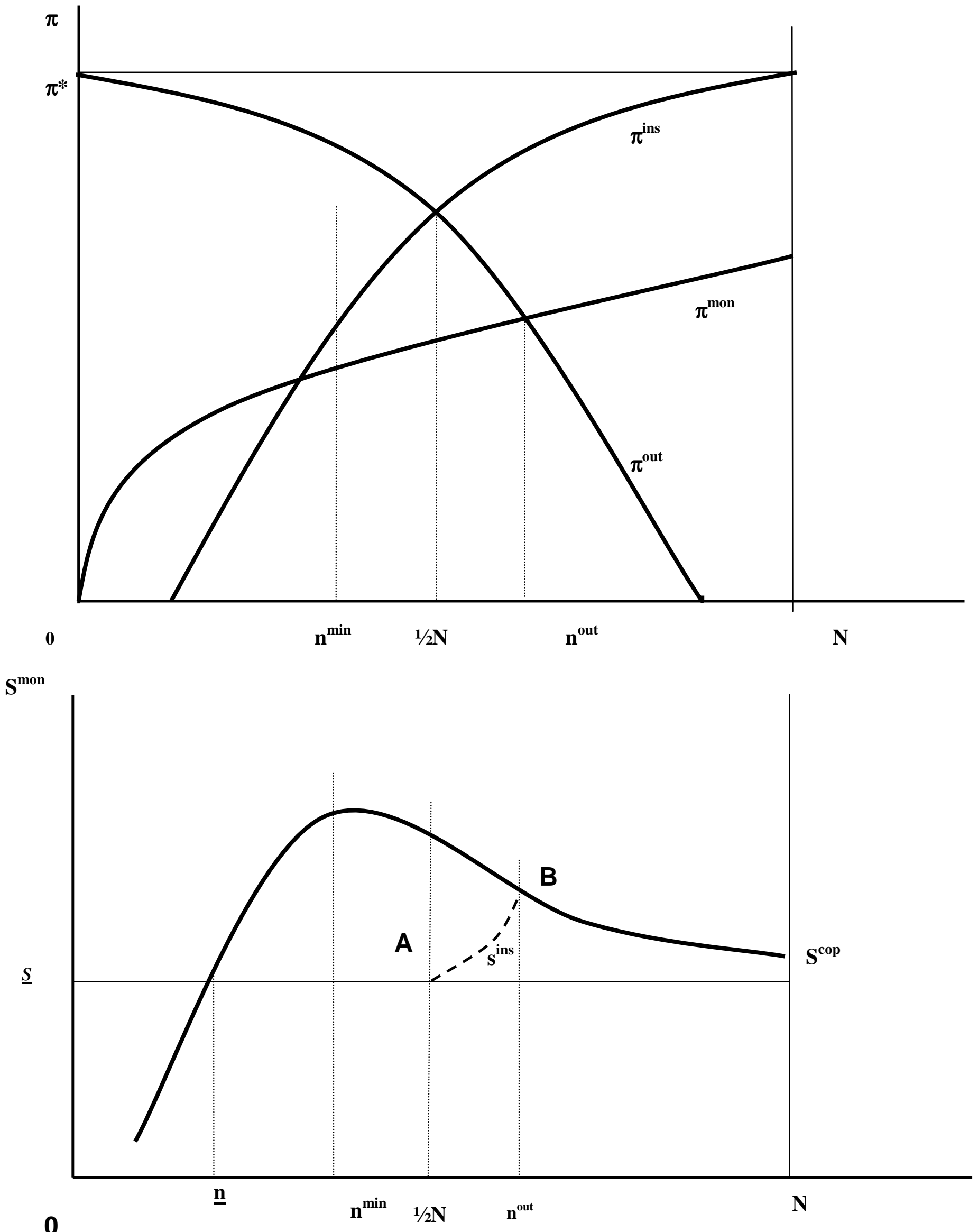
Figure 2 Profits and surplus without taxes and benefits
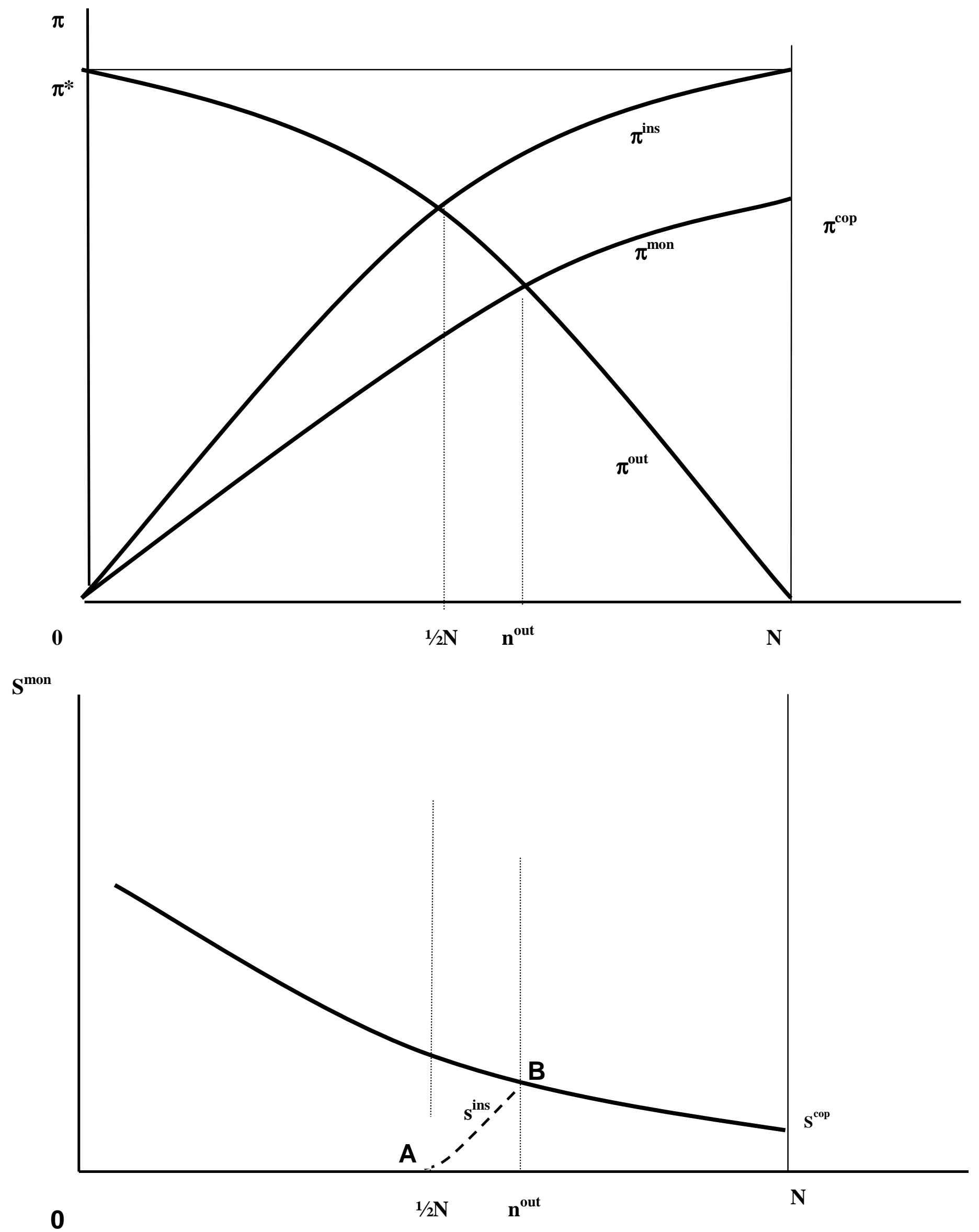

20 